\title{
The use of three anaesthetics for handling spotted rose snapper Lutjanus guttatus (Pisces, Lutjanidae) broodstock
}

Uso de tres anestésicos para el manejo de reproductores del pargo flamenco Lutjanus guttatus (Pisces, Lutjanidae)

\section{Zohar Ibarra-Zatarain', Leonardo Ibarra-Castro ${ }^{2}$, Luis Alvarez-Lajonchère ${ }^{3}$, Noemi García Aguilar ${ }^{2}$ and Juan Luis Sánchez-Téllez ${ }^{2}$}

\author{
${ }^{1}$ Alevines de México-Grupo Troutlodge, Ave. Miguel Alemán 927, Col. Centro, Mazatlán, Sinaloa, México. \\ zohar.ibarra@gmail.com \\ ${ }^{2}$ Centro de Investigación en Alimentación y Desarrollo A.C., Unidad Mazatlán, Avenida Sábalo Cerritos S/N, Mazatlán, \\ Sinaloa, Código Postal 82010, Apartado Postal 711, México \\ ${ }^{3}$ Grupo Piscimar, Calle 41 No. 886, Nuevo Vedado, La Habana, C.P. 10600, Cuba. alajonchere@gmail.com
}

\begin{abstract}
Benzocaine, 2-phenoxyethanol and MS-222 were tested as anaesthetics for several handling procedures with spotted rose snapper Lutjanus guttatus broodstock. Significant differences in time for induction and recovery were found with specific doses, as well as a direct correlation between the dose and the induction time. Each procedure demanded specific anaesthesia levels where the stage of deep anaesthesia should not be surpassed. The most effective agent for inducing deep anaesthesia was MS-222, with the least amount of time required for induction and recovery when using $100 \mathrm{mg} \mathrm{l}^{-1}$. It was followed by $250 \mu \mathrm{l} \mathrm{l}^{-1}$ of 2 -phenoxyethanol, which was less costly.
\end{abstract}

Key words: Fish sedation, handling broodstock, Mexico

\section{INTRODUCTION}

Spotted rose snapper Lutjanus guttatus (Steindachner, 1869), is an important food and recreational species that reaches high market prices (US\$ 5-8/kg), with a strong demand in America (Avilés-Quevedo et al. 2008). In fact, most snapper species (Lutjanidae) have been overexploited in wild fisheries (Watanabe et al. 2005, AvilésQuevedo et al. 2008). The species is a batch spawner with asynchronous ovarian development and a long reproductive season with two main spawning periods (Cruz-Romero et al. 1996). Most aquaculture research is carried out on spotted rose snapper in countries of Latin America with a Pacific coast, mostly in the field of induced spawning (Avilés-Quevedo et al. 2008, Herrera-Ulloa et al. 2010).

Handling the broodstock properly to minimize injury and stress is a critical component of the different culture procedures, especially with excitable species (McCarter 1992, Harvey \& Carolsfeld 1993, Bromage 1995). It is well established that stress will influence final oocyte maturation, ovulation and spawning of females to varying degrees, and it may reduce the flow of milt, and influence sperm density and/or motility in males (Harvey \& Carolsfeld 1993, Tucker 1998).

Sedation and anaesthesia are useful for handling fish with minimal trauma and stress, and there are several agents commonly applied in aquaculture. The use of inappropriate methods when applying anaesthetics/ sedatives, such as over- or under- dosing, can lead to potentially harmful or catastrophic results (Ross \& Ross 2008). High dosages are commonly used to reach the deepest level of anaesthesia without measuring the consequences. This type of anaesthetic administration can lead to severe damage or death, while the use of calculated dosages for the anaesthetic stages required, are safer and more practical (Tucker 1998).

The appropriate stage of anaesthesia to be administered will depend on the procedure being implemented (Harvey \& Carolsfeld 1993, Varner 2000, King et al. 2005, Ross \& Ross 2008). The combination of the correct anaesthetic agent, dose level and the length of exposure for the stage of anaesthesia desired must be found; this also depends on the environmental conditions, 
fish species, size, behaviour, and purpose (Harvey \& Carolsfeld 1993, Tucker 1998, Varner 2000, Ross \& Ross 2008).

The mode of action of each anaesthetic is slightly different, with varying degrees of narcosis, analgesia, and muscular relaxation for each agent and dose, which is especially important when a new species is studied (Harvey \& Carolsfeld 1993), or a new anaesthetic is applied on a given species (Malmstrom et al. 1993).

The aim of the present study was to test a series of experiments with spotted rose snapper broodstock to evaluate the doses required for each anaesthetic level, as well as the efficiency of three of the most commonly used anaesthetics: benzocaine, 2-phenoxyethanol, and tricaine methanesulfonate (MS-222), for common hatchery handling operations, and to determine if different procedures require different levels of anaesthesia.

\section{Materials ANd Methods}

Adult spotted rose snapper, held at the Research Centre for Food and Development (CIAD according to its Spanish acronym) at Mazatlan, Mexico were used. A total of 137 broodstock with a mean weight (mean \pm SE) of $468.6 \pm 14 \mathrm{~g}$ and $32.7 \pm 1.5 \mathrm{~cm}$ in length, caught near Sayulita Beach, Nayarit, were transported to the laboratory at Mazatlan, Sinaloa. Fish were stocked in a seawaterfilled $6 \mathrm{~m}$ diameter, $1 \mathrm{~m}$ deep $\left(25 \mathrm{~m}^{3}\right)$ vinyl-lined tank where seawater flow-through of 5 volumes per day as well as strong aeration were provided. These fish were fed a ration of 50\% fish (mostly skipjack) and 50\% frozen squid once daily to satiation, 6 days a week for 5 months prior to the experiments.

A bath anaesthesia procedure was adopted. Three of the most commonly used anaesthetics were studied: benzocaine, 2-phenoxyethanol, and tricaine methanesulfonate (MS-222), and 5 different dosages of each one were chosen, following the strategy given by Malmstrom et al. (1993). A baseline dosage was defined according to previous experience with other marine fish species (Harvey \& Carolsfeld 1993, Ross \& Ross 2008); and in the case of 2-phenoxyetanol a pilot study using the spotted rose snapper was conducted in the laboratory. Dosages were selected as follows: the minimum dose was half the second dose, which was taken as the baseline, the third dose was $125-150 \%$ of the second dose, the fourth was $150-200 \%$ of the second dose, and the fifth was $120-150 \%$ of the fourth dose. Only four fish were used when the lowest and the highest concentrations were applied, especially considering that fish were not going to be re-used as has occurred in other studies (Malmstrom et al. 1993), while eight or nine fish were tested when applying the other three concentrations. Each anaesthetic agent was assessed on different consecutive days during the morning hours, and each fish was used only once during the study.

For the experiment, a group of fish were encircled inside the communal tank with a fine, $7 \mathrm{~m}$ long net, then they were individually caught with a hand net $(0.80 \times 0.40 \mathrm{x}$ $0.30 \mathrm{~cm}$ ) made with a floating frame of sealed PVC pipes and elbows. The individual fish was left inside this net for at least 4-5 $\mathrm{min}$ before being introduced into the polyvinylchloride tank $(60 \times 35 \times 30 \mathrm{~cm})$ containing 301 of seawater with constant aeration $\left(101 \mathrm{~min}^{-1}\right)$ where the anaesthetic volume was well dispersed by vigorously shaking the water for a couple of minutes. Water quality parameters were measured continuously, and kept constant throughout the experiments; temperature was $28-29^{\circ} \mathrm{C}$, salinity was in the range of 34 to $35 \mathrm{~g} \mathrm{l}^{-1}$ and $\mathrm{pH}$ was at 7.5-7.6. Stock solutions of $25 \mathrm{mg} \mathrm{ml}^{-1}$ MS-222 (Argent Chemical Laboratories, Redmond, WA, USA) and $100 \mathrm{mg} \mathrm{l}^{-1}$ of benzocaine (Sigma, Toluca, Mexico) were prepared by mixing with ethanol, while 2-phenoxyethanol (Sigma, Toluca, Mexico) was poured directly into the anaesthetic tank with seawater and well mixed before fish were introduced. Anaesthetic solution was renewed after every fourth fish.

The anaesthetic stage definitions of McFarland (1959) modified by Summerfelt \& Smith (1990) and Ross \& Ross (2008), were followed. The deep sedation stage was identified as that in which the fish, having a normal equilibrium, did not react to visual stimuli, for example when hands were placed near their eyes. The next anaesthetic stage, light anaesthesia (the stage of partial equilibrium loss), was distinguished as that in which the partial loss of equilibrium was reached, starting when a spasmodic behaviour identified by erratic swimming was observed. The deep anaesthesia stage (the total loss of equilibrium) was identified as that of a total loss of equilibrium, with the fish lying at the bottom of the tank with their belly upwards, and few, but regular, ventilation opercular movements were observed. The surgical anaesthesia stage (the loss of reflex reactivity) was recognised when there was a total loss of reaction to all stimulants and the opercular movements were very slow and irregular. The respiratory and cardiac collapse level (medullary collapse of asphyxia stage) was characterized by the absence of opercular ventilation movements. 
After each fish had reached the deep anaeshesia stage (total loss of equilibrium), the fish was removed from the water, weighed to the nearest gram on a top-loading balance, its total length measured to the nearest $\mathrm{mm}$ thentagged with $1.2 \mathrm{~cm}$ PIT tags (Biomark, Idaho, USA) on the dorsal muscle close to the caudal fin, and assessed for its sexual development stage (in males by applying light abdominal pressure to check for the release of milt and its fluidity, and in females by cannulation with a polyethylene catheter). Then the fish were introduced into a recovery tank of the same capacity as that used for the anaesthetic bath, with a seawater flow-through of 71 $\min ^{-1}$ and constant aeration. Upon total recovery, the fish were transferred to another tank $\left(7 \mathrm{~m}^{3}\right)$ and not used again. Induction time for each anaesthetic stage, total exposure time, time outside the water, and recovery time were taken with a digital timer and recorded for each fish, together with their individual reactions to handling procedures and the behaviour observed during the entire process.

Additionally, to test the effects of each anaesthesia level, different handling procedures were attempted in each of the anaesthesia levels. Also, four fish were left for several minutes within the last two dosages of each anaesthetic to check for maximum recovery capacity.

Statistical differences between means were determined by one-way ANOVA followed by the Tukey test, with confidence intervals of $95 \%$, after the homogeneity of variances (Bartlett's test) and normality (KolmogorovSmirnov or Shapiro-Wilks) (Sokal \& Rohlf 1981) were demonstrated. Spearman rank correlation procedure was used to analyse correlations between dose and recovery time for each anaesthetic (Zar 1999).

\section{Results AND DISCUSSION}

Each anaesthetic showed significant differences in the time required for induction and recovery $(\mathrm{F}=7.84-15.32$, $P<0.05$, Dunn $P<0.05$ ). There was a negative and highly significant correlation between the dose and the induction time required for each anaesthetic stage for all substances tested ( $r=-0.727$ to $r=-0.973, P<0.01$ ) (Table 1). In addition, there was a low correlation between the dose and recovery time for each of the three anaesthetics $(P<$ 0.01 ) (Table 1), as reported for other species (Hseu et al.1998, Mylonas et al. 2005).

Table 1. Dosages, time to reach each anaesthetic stage, and total exposure and recovery times for spotted rose snapper Lutjanus guttatus (mean \pm standard error) / Dosis, tiempos para alcanzar cada estadio de anestesia, de exposición total y de recuperación del pargo flamenco Lutjanus guttatus (promedio \pm error estándar)

\begin{tabular}{|c|c|c|c|c|c|c|}
\hline \multirow{2}{*}{$\begin{array}{l}\text { Anaesthetic } \\
\text { concentrations } \\
\text { (Fish number } \\
\text { per trial) }\end{array}$} & \multicolumn{4}{|c|}{ Time to each anaesthetic stage $(\mathrm{s})^{*}$} & \multirow{2}{*}{$\begin{array}{l}\text { Total exposure } \\
\text { time (s) }\end{array}$} & \multirow{2}{*}{$\begin{array}{l}\text { Recovery } \\
\text { time (s) }\end{array}$} \\
\hline & $\begin{array}{c}\text { Deep } \\
\text { sedation }\end{array}$ & $\begin{array}{l}\text { Light anaesthesia } \\
\text { or partial loss of } \\
\text { equilibrium stage }\end{array}$ & $\begin{array}{l}\text { Deep anaesthesia } \\
\text { or total loss of } \\
\text { equilibrium stage }\end{array}$ & $\begin{array}{l}\text { Surgical anaesthesia } \\
\text { or loss of reflex } \\
\text { reactivity stage }\end{array}$ & & \\
\hline \multicolumn{7}{|c|}{ Benzocaine $\left(\mathrm{mg} \mathrm{l}^{-1}\right)$} \\
\hline $50(4)$ & $36 \pm 2$ & $77 \pm 17$ & $538 \pm 65$ & -- & 600 & $325 \pm 55$ \\
\hline $100(8)$ & $39 \pm 3$ & $60 \pm 4$ & $128 \pm 5$ & $192 \pm 15$ & $192 \pm 15$ & $189 \pm 68$ \\
\hline $150(8)$ & $33 \pm 2$ & $47 \pm 3$ & $89 \pm 4$ & $146 \pm 4$ & $146 \pm 4$ & $277 \pm 21$ \\
\hline $200(12)$ & $16 \pm 3$ & $34 \pm 8$ & $66 \pm 6$ & $116 \pm 8$ & $116 \pm 8$ & $250 \pm 38$ \\
\hline $300(8)$ & $18 \pm 3$ & $23 \pm 4$ & $53 \pm 5$ & $82 \pm 7$ & $82 \pm 7$ & $241 \pm 25^{1}$ \\
\hline \multicolumn{7}{|c|}{ 2-phenoxyethanol $\left(\mu \mathrm{l} \mathrm{l^{-1 }}\right)$} \\
\hline $125(4)$ & $33 \pm 1$ & $177 \pm 19$ & --** & -- & 600 & $70 \pm 4$ \\
\hline $250(9)$ & $24 \pm 4$ & $45 \pm 4$ & $126 \pm 12$ & $217 \pm 28$ & $217 \pm 28$ & $75 \pm 10$ \\
\hline $375(8)$ & $16 \pm 2$ & $36 \pm 3$ & $76 \pm 4$ & $141 \pm 17$ & $141 \pm 17$ & $180 \pm 7$ \\
\hline $500(12)$ & $12 \pm 1$ & $33 \pm 3$ & $72 \pm 3$ & $122 \pm 18$ & $122 \pm 18$ & $160 \pm 34$ \\
\hline $750(8)$ & $12 \pm 2$ & $23 \pm 5$ & $49 \pm 5$ & $120 \pm 11$ & $120 \pm 11$ & $184 \pm 16^{1}$ \\
\hline \multicolumn{7}{|l|}{$\mathrm{MS}-222\left(\mathrm{mg} \mathrm{l}^{-1}\right)$} \\
\hline $50(4)$ & $34 \pm 4$ & $75 \pm 11$ & $258 \pm 21$ & -- & 300 & $62 \pm 13$ \\
\hline $100(9)$ & $20 \pm 4$ & $31 \pm 5$ & $120 \pm 5$ & $172 \pm 9$ & $172 \pm 9$ & $113 \pm 13$ \\
\hline $125(9)$ & $13 \pm 2$ & $25 \pm 4$ & $88 \pm 5$ & $139 \pm 14$ & $139 \pm 14$ & $99 \pm 10$ \\
\hline $150(12)$ & $14 \pm 2$ & $21 \pm 2$ & $64 \pm 7$ & $125 \pm 11$ & $125 \pm 11$ & $123 \pm 9$ \\
\hline $175(8)$ & $13 \pm 1$ & $22 \pm 2$ & $55 \pm 4$ & $117 \pm 7$ & $117 \pm 7$ & $198 \pm 6^{2}$ \\
\hline
\end{tabular}

${ }^{*}$ McFarland (1959) modified by Summerfelt \& Smith (1990) and Ross \& Ross (2008)

** No fish reached aesthetic level partial loss of equilibrium, light anaesthesia.

${ }^{1}$ Three fish died when fish were left for $10 \mathrm{~min}$.

${ }^{2}$ Two fish died when fish were left for $5 \mathrm{~min}$. 
The fish reached the deep sedation and light anaesthesia stages with the lowest doses of each anaesthetic, although by simple observation, the outset of the following light anaesthesia level was easier to distinguish, based on the observation of agitated behaviour at the start of the partial loss of equilibrium. Light anaesthesia was the highest stage attained with the lowest dose of 2-phenoxyethanol used $\left(125 \mu \mathrm{ll}^{-1}\right)$ within the longest exposure time allowed (Table 1).

The shortest time for induction and recovery producing deep sedation, light anaesthesia (partial loss of equilibrium) and deep anaesthesia (total loss of equilibrium) were attained with $100 \mathrm{mg} \mathrm{l}^{-1}$ of MS-222, followed by $250 \mu 1 \mathrm{l}^{-1}$ of 2-phenoxyethanol, and $100 \mathrm{mg} \mathrm{l}^{-1}$ of benzocaine (Table 1, Fig. 1). For surgical anaesthesia (total loss of reflex reactivity stage), the shortest induction time required with the lowest dose of one of the anaesthetics tested was reached at $100 \mathrm{mg} \mathrm{l}^{-1}$ with MS$222(172 \pm 9 \mathrm{~s})$, although the shortest recovery time was with $250 \mu 11^{-1}$ of 2-phenoxyethanol (75 $\left.\pm 10 \mathrm{~s}\right)$ (Table 1). The best recovery time with the longest exposure, reaching surgical anaesthesia, was with $250 \mathrm{ml} \mathrm{l}^{-1}$ of 2phenoxyethanol (Table 1).

Anesthetizing other marine fish broodstocks with MS222 and 2-phenoxyethanol requires effective doses similar to those found in the present study (Garcia 1992, Emata et al. 1994, Tucker 1998, Ross \& Ross 2008), and half the dose previously applied to spotted rose snapper broodstock at the CIAD laboratory (Ibarra-Castro \& Duncan 2007).

Maximum dosages tested were those most likely to be at or near the upper limit for the safe application of these anaesthetic agents, since the recovery time needed was long; when the exposure time was extended to $10 \mathrm{~min}$ using benzocaine and 2-phenoxyethanol and $5 \mathrm{~min}$ in MS222 , the stage of surgical anaesthesia was reached in all cases, producing the only deaths found in the experiments.

Most broodstock handling procedures, especially intramuscular tagging/implant applications, weighting, and total length measurements were only possible when the fish reached deep anaesthesia (total loss of equilibrium), and fish did not have to reach the stage of surgical anaesthesia (total loss of reflex). Furthermore, surgical anaesthesia proved to be both unnecessary and dangerous because of the possibility of death. This anaesthetic stage is therefore inappropriate for handling broodstock of this species.

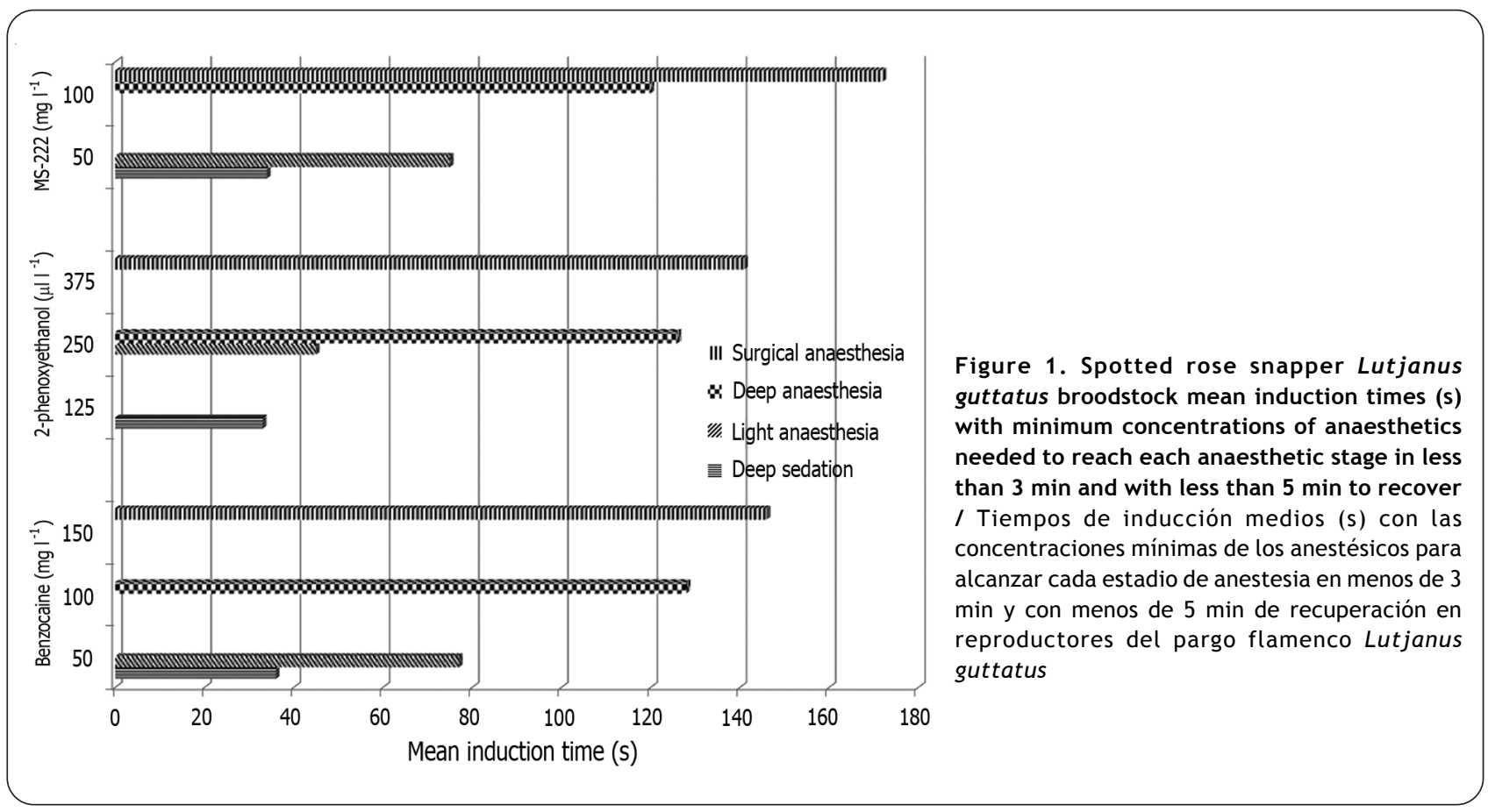


When total exposure time was 5 min with $175 \mathrm{mg} \mathrm{l}^{-1}$ MS-222, and 10 min with $300 \mathrm{mg} \mathrm{l}^{-1}$ of benzocaine, and 750 $\mu 11^{-1}$ of 2-phenoxyethanol, the respiratory and cardiac collapse level was reached, and recovery time was about 20 min or longer, with several fish dying when they were maintained for 1-3 min after opercular respiratory movements had ceased (Table 1). No deaths occurred during the following $24 \mathrm{~h}$.

Many of the anesthetics applied today can potentially harm human beings if they are misused (Ackerman et al. 2005), including MS222, benzocaine, clove oil, AQUI-S ${ }^{\circledR}$, 2-phenoxyetanol, and others, which have shown to be harmful to humans if swallowed, inhaled or absorbed through the skin, as well as being severe eye and skin irritants (Ross \& Ross 2008). Also, depending on the species, certain agents have been reported to have side effects on fish, such as 2-phenoxyethanol, (Summerfelt \& Smith 1990, Harvey \& Carolsfed 1993, Hseu et al. 1998, Ross \& Ross 2008) and reports are also found regarding their narrow margin of safety (Varner 2000). For cod Gadus morhua, a slow induction time but short recovery time without producing mortality was shown (Mattson \& Riple 1989). On the other hand, Hseu et al. (1998) found 2phenoxyethanol to be very convenient for goldlined sea bream (Sparus barba), and Watanabe et al. (2006) reported good results in nine of the most important marine fish species cultured in Japan. This agent also has a positive and important collateral effect as a chemotherapeutic agent (McCarter 1992, Harvey \& Carolsfed 1993).

As with other anaesthetics, MS-222 has been shown to have drawbacks (Harvey \& Carolsfeld 1993, Neiffer \& Stamper 2009). The improper use of MS-222 can decrease fish viability, distort physiological data or result in death (Carter et al. 2011), although it is the most widely used anaesthetic agent for fish (Tucker 1998), and the only one currently approved by the USA Food and Drug Administration for use on food fish (Varner 2000), and it has also been approved in several other countries (Ross \& Ross 2008, Carter et al. 2011).

Other agents such as clove oil or its principal active ingredient, Eugenol (Ross \& Ross 2008, Benetti et al. 2008) could be further tested in order to continue improving the use of anaesthetics to facilitate handling, sampling and the transfer of spotted rose snapper broodstock. Clove oil has been used as a mild topical anesthetic for ages, especially in dentistry, and it has been recommended as a useful alternative to MS222 due to its effectiveness, the low dose required, its short induction time, its natural origin, and low cost (Sladky et al. 2001, Ross \& Ross 2008), with good results in fresh water, diadromous and marine fishes (Sladky et al. 2001, Benetti et al. 2008).

In the present study with spotted rose snapper broodstock, we demonstrated that different procedures required different levels of anaesthesia, in which anaesthesia may last longer and recovery may be slower. The shortest induction time was with MS-222, followed by benzocaine and finally 2-phenoxyethanol, while recovery time was shortest with 2-phenoxyethanol, followed by MS-222 and benzocaine, as shown in other species (Sladky et al. 2001). MS-222 with a dose of 100 $\mathrm{mg}^{-1}$ had the highest efficacy with an induction time of 3 min or less to reach the required anaesthesia level, in our case deep anaesthesia, and a recovery time shorter than 5 min, without negative side effects. Following with 250 $\mu 11^{-1}$ of 2-phenoxyethanol, may highlight an inexpensive alternative showing good results in the present species, without the negative effects reported for other species.

\section{ACKNOWLEDGMenTs}

We wish to express our thanks to Victor Ortega and his crew for catching the fish, and to Biol. Pedro Ulloa and his staff at CRIP Bahía de Banderas for their hospitality. Authors are grateful to the CIAD Marine Fish Culture Program members for their assistance and permanent interest. Thanks are also due to L. Ockelmann-LoBello and M. Rivas for editing earlier versions of the manuscript and for their useful comments and recommendations on the manuscript. This study was partially supported by project SAGARPA-CONACyT 378.

\section{LITERATURE CITED}

Ackerman PA, JD Morgan \& GK Iwama. 2005. Anesthetics. Supplement to the CCAC guidelines on: the care and use of fish in research, teaching and testing. [on line] $<$ http:// www.ccac.ca/en/CCAC_Programs>

Avilés-Quevedo A, JM Mazón-Suástegui \& F CastellóOrvay. 2008. Avances en el cultivo del Pargo Flamenco, Lutjanus guttatus. Un ejemplo a seguir de los pescadores de Bahía Concepción, en Baja California Sur. Industria Acuícola 4: 4-7.

Benetti D, MR Orhun, B Sardenberb, B O'Hanlon, A Welch, R Hoenig, I Zink, JA Rivera, B Denlinger, D Bacoat, K Palmer \& F Cavalin. 2008. Advances in hatchery and grow-out technology of cobia Rachycentron canadum (Linnaeus). Aquaculture Research 39: 701-711. 
Bromage N. 1995. Broodstock management and seed qualitygeneral considerations. In: Bromage NR \& RJ Roberts (eds). Broodstock management and egg and larval quality, pp. 124. Blackwell Science, Oxford.

Carter KM, CM Woodley \& RS Brown. 2011. A review of tricaine methanesulfonate for anesthesia of fish. Reviews in Fish Biology and Fisheries 21: 51-59.

Cruz-Romero M, EA Chavez, E Espino \& A Garcia. 1996. Assessment of a snapper complex (Lutjanus spp.) of the eastern tropical Pacific. In: Arreguin-Sánchez F, JL Munro, MC Balgos \& D Pauly (eds). Biology and culture of tropical groupers and snappers. ICLARM Conference Proceedings 48: 331-337.

Emata AC, B Eullaran \& TU Bagarinao. 1994. Induced spawning and early life history description of the mangrove red snapper, Lutjanus argentimaculatus. Aquaculture 121: 381-387.

Garcia LMB. 1992. Lunar synchronization of spawning in sea bass, Lates calcarifer (Bloch): effect of luteinizing hormone-releasing hormone analogue (LHRHa) treatment. Journal of Fish Biology 40: 359-370.

Harvey B \& J Carolsfeld. 1993. Induced breeding in tropical fish culture, $144 \mathrm{pp}$. International Development Research Centre, Ottawa.

Herrera-Ulloa A, J Chacón-Guzmán, G Zúñiga-Calero \& R Jiménez-Montealegre. 2010. Spotted rose snapper (Lutjanus guttatus) aquaculture research and development as socio-economic alternative for Costa Rican fishing communities. World Aquaculture 41: 20-22.

Hseu JR, SL Yeh, YT Chu \& YY Ting. 1998. Comparison of efficacy of five anaesthetics in goldlined sea bream, Sparus sarba. Acta Zoologica Taiwanica 9: 35-41.

Ibarra-Castro L \& NJ Duncan. 2007. GnRHa-induced spawning of wild-caught spotted rose snapper Lutjanus guttatus. Aquaculture 272: 737-746.

King VW, B Hooper, S Hillsgrove, C Benton \& DL Berlinsky. 2005. The use of clove oil, metomidate, tricaine methanesulphonate and 2-phenoxyethanol for inducing anaesthesia and their effect on the cortisol stress response in black bass (Centropristis striata L.). Aquaculture Research 36: 1442-1449.

Malmstrom T, R Salte, HM Gjoen \& A Linseth. 1993. A practical evaluation of metomidate and MS-222 as anaesthetics for Atlantic halibut (Hippoglossus hippoglossus L.) Aquaculture 113: 331-338.

Mattson NS \& TH Riple. 1989. Metomidate, a better anesthetic for cod (Gadus morhua) in comparison with benzocaine, MS-222, chlorobutanol, and phenoxyethanol. Aquaculture 83: 89-94.
McCarter N. 1992. Sedation of grass carp and silver carp with 2-phenoxyethanol during spawning. Progressive Fish Culturist 54: 263-265.

McFarland WN. 1959. A study of the effects of anaesthetics on the behaviour and physiology of fishes. Publication Institute of Marine Science 6: 23-55.

Mylonas CC, G Cardinaletti, I Sigelaki \& A PolzonettiMagni. 2005. Comparative efficacy of clove oil and 2phenoxyethanol as anaesthetics in the aquaculture of European sea bass (Dicentrarchus labrax) and gilthead sea bream (Sparus aurata) at different temperatures. Aquaculture 246: 467-481.

Neiffer DL \& MA Stamper. 2009. Fish sedation, anesthesia, analgesia, and euthanasia: Considerations, methods, and types of drugs. ILAR Journal 50: 343-360.

Ross LG \& B Ross. 2008. Anaesthetic and sedative techniques for aquatic animals, $240 \mathrm{pp}$. Blackwell Publishing, Oxford.

Sladky KK, CR Swanson, MK Stoskopf, MR Loomis \& GA Lewbart. 2001. Comparative efficacy of tricaine methanosulfonate and clove oil for use as anesthetics in red pacu (Piaractus brachipomus). American Journal of Veterinary Research 62: 337-342.

Sokal RR \& FJ Rohlf. 1981. Biometry, 859 pp. Freeman and Co., New York.

Summerfelt RC \& LS Smith. 1990. Anesthesia, surgery, and related techniques. In: Schreck CB \& PB Moyle (eds). Methods for fishery biology, pp. 213-272. American Fisheries Society, Bethesda.

Tucker JW Jr. 1998. Marine fish culture, 750 pp. Kluwer Academic Publishers, Boston.

Varner PW. 2000. Anesthetics. In: Stickney RR (ed). Encyclopedia of aquaculture, pp. 33-38. John Wiley \& Sons, New York.

Watanabe K, M Takahashi, M Nakagawa, K Ota, J Sao \& T Hotta. 2006. Effectiveness of 2 -phenoxyethanol Anesthesia of Fish Cultured in Japan. Suisan Zoshoku 54: 255-263.

Watanabe WO, DD Benetti, MW Feeley, A Davis \& RP Phelps. 2005. Status of artificial propagation of mutton, yellowtail, and red snapper (family Lutjanidae) in the Southeastern United States. American Fisheries Society Symposium 46: 517-540.

Zar JH. 1999. Biostatistical analysis, 944 pp. Prentice-Hall, Englewood Cliffs. 